Vantage: Journal of Thematic Analysis

ISSN: 2582-7391

A Multidisciplinary Publication of Centre for Research,

Maitreyi College, University of Delhi

April 2021, Volume 2, Issue 1

Original Research Article

\title{
Anxieties and Fears: A Sociological Study of Mental Health of Students in COVID-19 Pandemic
}

\author{
Rashi Bhargava*, Nayana Borgohain, I. L. Prathyusha Naidu, Samiksha Bhatnagar, \\ Shipra Lakra and Vani Shukla \\ Department of Sociology, Maitreyi College, Bapu Dham, Chanakyapuri, \\ New Delhi-110021, India \\ *Correspondence: rbhargava@maitreyi.du.ac.in
}

\begin{abstract}
This paper aims to explore the impact of COVID-19 and the implications of pandemic induced changes on the mental health of students. The study was conducted amongst currently enrolled college (undergraduate) and 12th-grade students in Delhi-NCR. Apart from this, parents and professionals were also consulted. This paper approaches the issue of mental health from a sociological perspective to create a comprehensive understanding of the factors which create anxieties and fears amongst students in times of COVID-19 induced pandemic. The study began with the assumption that mental health is not only a biological and psychological issue but needs to be contextualized in societal structures and societyindividual relationship. Students as a social group are primarily affected by institutions of education and family, the study thus explores how the three are intertwined. The paper ends with the contention that social integration and regulation are primary concepts through which individual resilience can be studied, understood and theorised. It also highlights that despite the commonsensical belief that the current times are different from the societal normal, a study like this offers a window to understand the structural continuities of the pre-pandemic period into the pandemic period.
\end{abstract}

KEYWORDS: Students, mental health, education, family, COVID-19 


\section{INTRODUCTION}

The highly contagious novel Coronavirus has threatened the lives of millions of people across the world. In India, the number as on 3rd April, 2021 was recorded at 12.3 million (and counting) while the death toll is at 163000 (and counting) (Ray, 2021). COVID-19 has been declared a public health emergency of global concern. In the strive to contain this pandemic the governments across the globe (India included) have taken multiple measures which include lockdowns, quarantines, closure of educational institutions and other public places, restricting mobility of individuals. These measures curtailed social and public life, reorganized home and work spaces, led to an economic downturn, caused emotional stress and created a 'new normal' which as the situation exhibits, is here to stay. They are often systemic in nature, designed to curtail the spread of the virus while the latent impact of the pandemic (numerous fears and anxieties producing and produced by mental health issues) has only been touched upon sparsely.

Despite numerous attempts to create awareness about mental health problems, mental health is considered an aberration resulting in stigma. For instance, the World Health Organisation (WHO) (n.d.) on its official website defines health as a state of complete physical, mental and social well-being and not merely the absence of disease or infirmity, stating, 'there is no health without mental health'. Yet, in popular imagination, a mental health patient is considered to be a 'weak' individual and 'seeking help' or therapy is still a taboo. Even during the process of therapy (undertaken mostly by clinical psychologists), the psyche of the individual is interrogated and the fears that the individual has suffered are often understood as 'personal'. Thus, the individual is the unit that is paid most attention to while the role of social structures in understanding mental health concerns is often ignored. This allows us to underscore the sociological contention that the individual is embedded within the larger socio-cultural, historical, economic and political matrix.

In this regard, Durkheim's study of Suicide (1897) is extremely relevant. He critiqued the psychological perspective and argued that suicide is not an individual act nor a personal action, but primarily a social phenomenon which results from fracturing or transformation of significant social bonds in an individual's life. Consequently, he argued that a study of a phenomenon like suicide requires an interrogation of societal 
forms, organizations and institutions like education, society, belief systems, political institutions, religion, family, law, etc. responsible for establishing and sustaining social integration and regulation. Following Durkheim, our contention is that a sociological study on mental health is not just the study of the qualities of individuals but also of social reality and circumstances. This is particularly interesting in the situation of the pandemic itself. The pandemic has not only disrupted our 'normal' lives but has also created a rupture in every part of our social being.

However, one cannot disregard the significance of individual agency in making sense of and constructing one's reality. The scholars from symbolic interactionist school of thought, especially G.H. Mead and Erving Goffman can help address this gap. G.H. Mead (1934) argued that the self is an emergent product of social experience. Only by being able to take others' perspectives can we gain a viewpoint from outside of our own egos from which to think about and evaluate our personal identities (Joas, 1997), as there is a general societal expectation to look and act in a certain way. According to Erving Goffman (1956), interactions between individuals depend on their environment which compels them to seek the meaning of each situation with the aim of achieving control over it. This is how we handle the impressions other people will have of us. It is here we find the students trying to deal with their present circumstances and devise ways to deal with their anxieties and fears.

In the light of the above, the focus of this paper is to look at the impact of the pandemic and the lockdown on the mental health of the students, locate their fears and anxieties and their attempts to cope with it. It is imperative to mention at the outset that the choice of the topic and the theme of the study was personal for us since we are part of the group that we intended to study and are experiencing a similar situation as our respondents.

\section{METHODOLOGY}

During the pandemic, the most common emotion faced by the students is 'fear' of the unknown brought about by the event of the pandemic and subsequently that of failure, which makes them anxious, stressed and uncertain. The recent news of the death by suicide of a class $\mathrm{X}$ student in Kerala because of lack of facilities to access 'online 
classes', an alternative to physical classrooms during the lockdown, fearing that her progress will be hampered in school, in The Hindu (Express Web Desk, 2020) and covered by Naha (2020) is a case in point ${ }^{1}$. In addition, being confined to the household has thrown open many questions with regard to family structures and dynamics.

Thus, we were faced with the question, with sudden changes brought about by the pandemic, what leads to feelings of stress, fears and anxieties amongst the students? We were also interested in knowing if these feelings have any continuity between the pre-pandemic and the pandemic period. Following from these broad questions, the main objectives of this study are: firstly, to arrive at a sociological understanding of the impact on the mental health of students during COVID-19. Secondly, map the effects of 'virtual classrooms' and sudden change in education process on students and explore their coping strategies. Lastly, to explore the relationship between mental health of students, education processes and their families during the lockdown. In the present study, the word 'mental health' refers to stress-related issues like anxiety, depression, attention deficit disorder, etc. and not other disabilities such as autism, Parkinson's, dementia, Alzheimer's, schizophrenia, etc.

Since we are living through the pandemic, the data regarding the same is minimal. Consequently, the conducted research is exploratory in nature and focuses on understanding and exploring the various dimensions and factors affecting mental health of the students in schools and colleges in Delhi- NCR (National Capital Region) during the COVID -19 pandemic. Snowball sampling technique was used in the research given the limited time to conduct the research. The questionnaires were filled and interviews were conducted with respondents' consent. The target group for the research were college and 12th class students which were a total of 110 respondents studying in DelhiNCR. The majority of our respondents were pursuing their graduation in social sciences and humanities. The proportion of female respondents was more than that of males. These respondents were divided into two categories (Category A and Category B)

1 Another article in The Indian Express dated 3rd June, 2020 stated that Kerala has started First Bell, a programme that began on June 1 as part of which classes are available through Kite Victers, a government run online portal that can be accessed through an app or through television channels. The girl's father, a daily wage labourer said she was upset about not being able to attend classes the family doesn't have a smartphone and their TV hadn't been working for months. 
depending upon the year in which they were enrolled, since this seemed to have a noteworthy impact on them and their fears and anxieties. Category A consisted of students from final year of graduation and 12th class which were 23 and 21 in number respectively. Category B consisted of students from first and second year of graduation are 12 and 50 respectively. Additionally, we also interacted with a doctor, professionals (2) and parents (5).

Keeping in mind the safety and precautionary guidelines for the pandemic which includes physical distancing, primary data was collected through an online survey using questionnaires (Google forms) which were circulated via emails and other social media platforms. The questionnaires consisted of both MCQs (Multiple Choice Questions) and open-ended questions. They were divided into four main themes: one, students' responses to changes in the processes of teaching, learning and evaluation viz. online classes, submission of internal assessment and online exams. Two, students' experiences of being confined to their homes which focused on family relationships and dynamics. Third, students' notions of productivity and leisure, their dreams and future aspirations. Fourth, to gauge their discomfort, fears and anxieties in the current situation, uncertainty with regard to their future plans and their coping strategies. Once the initial survey was accomplished, virtual interviews were conducted with the set of people who answered in affirmation for being interviewed in their Google forms. The interviews conducted were semi-structured which consisted of 18 questions that largely focused on obtaining in-depth information on the themes outlined in the questionnaire. Secondary data was collected through news, popular articles, academic writings, journalistic pieces, online articles, blogs etc.

\section{DATA AND FINDINGS}

As outlined in the introduction, our study attempted to transcend the commonsensical notion that mental health problems are a result of individual psyche and argue that they are a result of socio-cultural, economic and political tensions and contradictions of the times. In the current pandemic situation, we also have to take into account the fear of contagion. The attempts to curtail the spread of the virus has created a situation that is extraordinary and has called into question everything that was taken for granted and considered 'normal'. In students' lives, the two most essential social institutions of socialization are education and family (Horton \& Hunt, 1985). Over time, many 
changes have occurred in these two institutions. With macro changes in the global economic and political systems, most scholarly engagements over decades have shown that the purpose of education has changed from socializing the young to making them ready to take a place in the neo-liberal market economy (for instance see, Sen, 1999; Chopra \& Jeffery, 2005). The family structures too have transformed and thus need to be paid attention to.

\subsection{Online mode of teaching: From physical to digital classroom}

The process of teaching and learning in schools and colleges across the country has been shifted to an online platform as the most viable solution to carry forward the curriculum. When asked how effective the online classes were, majority of our respondents said that they are still struggling with the change while a clear 38\% said that they are not effective. With respect to the shift to online classes, $72 \%$ of the respondents do not prefer this change as they believe that e-learning is a difficult learning tool. They shared that the pre-pandemic situation was better because it was mediated through physical presence and close interaction with faculty and peers which e-learning lacks. Staying home gives them a number of reasons to be distracted (many hinted at how the home is not the ideal setting for work) resulting in lesser participation and interaction in classes. For instance, a second year student of Applied Psychology, said

Online classes are not fulfilling and become overwhelming at times, it is very difficult to stare at a rectangular screen all day long as it makes me think that what has the world come to that we seriously have to study from a screen and the classroom environment is missing. It becomes a burden.

Furthermore, students whose courses are practical based shared that they find it really hard to learn through the online medium, as shared by two respondents, one pursuing engineering and the other pursuing journalism.

Interaction with parents also revealed that they too did not prefer online mode of teaching, however considering the current situation it is the best option available. They added that it is not a sustainable option since it will hamper the holistic growth of their children. They also shared their concerns about their children's future which might get affected in the event of the pandemic. 
The online learning and teaching process also included submission of assignments, projects, presentations and tests which was uncomfortable for $57 \%$ of our respondents. The reasons given were: they had to meet strict deadlines which were sometimes difficult for various reasons like internet connectivity problems, lack of space (at home) to finish their work or lack of reading material (especially for out-station students). This often resulted in feelings of pressure, anxiety and irritation.

With regard to online examination, a strong opposition was noticed. Most respondents (88.2\%) believed that online exams should not happen, because: firstly, they are discriminatory because of the huge digital divide ${ }^{2}$ between the students. Secondly, many out-station students who are now back home do not have the requisite study material with them because of the sudden lockdown. Thirdly, students saw their homes lacking in proper space and environment for taking an examination. Hence, the fear that online examinations might hamper their chances at good results and better future.

These new ways to continue the teaching, learning and evaluation process have brought forth issues of inclusivity and accessibility which are contingent on the socio-economic and regional background of the student. This issue is symptomatic of the wider malaise that plagues the education system in India but has become more pronounced in the current situation. It raises serious concerns about digital divide and problem of equity which often translates into anxieties and fears.

\subsection{Relations within the family: Pre-pandemic to pandemic period}

During the lockdown, many students were confined to their houses with their families which has had both positive and negative impacts. The lockdown period gave them time to interact with each other more which they saw as a positive development. Five of our respondents talked about the opportunity it provided to bond with their family members which was missing in the pre-pandemic period due to their busy schedules. This was particularly important for out-station students who stay in hostels and a prolonged stay at home due to the lockdown has given them more time to catch up with their family

\footnotetext{
2 By digital divide, most respondents meant that a number of students who either live in areas where there is limited/ no internet connectivity or lack smartphones/laptops might not be able to perform satisfactorily despite being well-prepared to take the exams.
} 
members. Some respondents also shared that fights took place within the family in the initial days of the lockdown but as time passed, they have become more comfortable with their family members.

However, in some cases, respondents faced clashes of ideas and thoughts within their family settings and lack of communication between them and their parents emerged as a cause of concern for them. These mainly concerned their future, career plans, privacy, (lack of) space, utilization/waste of time and academic performance. A number of them, especially six outstation students, felt that their parents' dream and expectations did not match theirs often leading to alienation from their parents. The students feel that they have lost their independence especially with regard to their thought processes and lifestyle. A History Honours student shared how college provided a change of place and helped her get away from the family space. She said,

particularly when there is a fight in our family, I just want leisure but I am not able to get it and when I am stressed or when I am panicking, it feels like a cage.

College for students is not only about education but also a primary space for socializing. Few of our respondents differentiated between two kinds of family, one which is by birth or blood ties and the other that they choose by socializing with other members of the society by making friends. In the event of the pandemic, their interactions with their friends and in some cases with their partners (although none of the respondents mentioned it outrightly) has been limited to virtual spaces which are embedded within the space of the family, hence not as freely available as the space provided by educational institutions. Thus, the lockdown may have given them an opportunity to bond with their families of birth but it has also led to limited interaction with their families of choice (friends).

Another aspect that affected our respondents was with regard to the family dynamics often closely related to patriarchal relations. For a second year student of Sociology Honours, more time with her family highlighted the patriarchal set up of the family which eventually led to stress. She said,

I live in a joint family. Everything depends on my other relatives too and what they say and what is accumulated in their minds... I've been fighting with my 
dad...whatever my grandmother says he accepts it blindly and it starts to mess up with my head and I don't have anything to distract my mind.

Another college student said that she noticed how her family treated her brother and herself differently. She said,

I see discrimination like my brother roams around shirtless but when I wear a

spaghetti or something they all get curious so I hate it and I become really

triggered...and they have a very vague explanation that you are a girl.

Issues like these did cause an argument between her and her parents. This instance shows how the family also operates as a gendered space which existed even in the prepandemic period but has become more visible in the pandemic situation.

The changes that have taken place during the lockdown has given $54 \%$ of the respondents a combination of both positive (love, togetherness) and negative (irritation, frustration) feelings. In some cases, strained relationships within the family has led to strong feelings of discomfort and unease amongst our respondents.

\subsection{Productivity and Leisure}

Most of the respondents were very vocal about productivity and leisure activities. Almost $40 \%$ of the respondents felt that they are not being productive or that they aren't "doing enough" during this period of the lockdown.

In some cases, the respondents (five in total) clearly mentioned that they could not relate to their homes as a workspace which has an effect on their work schedules and productivity. For them work and home are two distinct spheres. They relate home more to a space of leisure and comfort. This idea of home makes it difficult for them to have a proper routine or 'make the best out of the lockdown' (i.e. to be productive) which makes them anxious and worried about their future aspirations and goals.

Quite a few respondents also attributed their lack of 'productivity' to cancellation of exams and being stuck at home for a long time. Not being able to 'do much' makes them feel that they will be left behind in the race, especially when the lockdown has given them more time to pursue things that they could not do earlier. This was put succinctly by a student of second year, Psychology Honours. She opined that society is seeing quarantine 
as an opportunity in which they can achieve many things and it has now become a race, and they might fall behind if their time is not put to proper use.

There was also pressure on the respondents from their parents to utilize their time instead of 'wasting' it on social media or OTT (Over The Top) platforms like Netflix, Hotstar etc. With regard to the expectation of family members, approximately $60 \%$ of the respondents feared disappointing or not being able to meet the expectations of their family. Hence, they tried to engage in various activities and if they could not, it led to guilt and anxiety. A second year student of Sociology Honours, mentioned how her parents urged her to either take up online courses or learn a new language in order to be productive. They also told her not to sit idle and waste her time. Similar sentiments were voiced by parents, as was evident in the response of the mother of a second year student who stated that something needs to be done for their child's productivity as they are not able to go to college anymore. She believes that the child should be more creative or universities should come forward with tailored programmes, both academic and extracurricular in nature, as they need some way to be more productive. This was further corroborated by the response of Dr. Mercian Daniel ${ }^{3}$ who shared that the expectations and the pressure to perform bring up concerns regarding mental health among students. Given the family structures and dynamics, the interests of the family often take priority over those of the individual, and decisions affecting one's personal life.

Although, not all respondents felt burdened and said that one of the positive aspects of the lockdown was that they had time to work on themselves. They have learned how to manage time better and how to spend time with his/her own self. Yet, this calls into question the notion of productivity in current societal settings. It is evident how we have internalized the pressure to perform better so much that even in these tough times we think of performing the best at everything and consequently burdening ourselves.

\subsection{Anxiety, fears and coping mechanism}

\footnotetext{
3 Dr. Mercian Daniel is one of the professionals we interacted with. He has completed his MPhil. in psychiatric social work and $\mathrm{PhD}$ in public health with a specialization in mental health, where he engaged with people diagnosed with schizophrenia.
} 
The feeling of 'not knowing' what will happen in the coming days coupled with the fear of their loved ones being affected by the virus is another cause of anxiety and fear among the respondents. Approximately $75.45 \%$ of our respondents shared that they felt trapped and caged during the lockdown. This has caused changes in their sleeping patterns and created regular feelings of helplessness and frustration. Uncertainty about their future plans with regard to higher education or employment was a major cause for concern for most respondents. Two students of twelfth grade who have given their board exam said that they are scared because this year they were supposed to get admission in college but now they have no clue. Most respondents (approximately $45.23 \%$ ) who are enrolled in undergraduate courses, felt that the global pandemic will have an effect on their careers; the economy is suffering and running in losses which will affect internship, job and career opportunities. Some respondents also shared that their plans to go abroad for further studies have been put on hold due to the pandemic and the inability to realize their dreams scares them. Thus, their issues can be broadly put into three categories - firstly, uncertainty about career/higher studies (62.3\%); secondly, continuously changing university guidelines especially with regard to academic calendar and online exams which might lead to lower grades (45.6\%) and thirdly, financial problems that might come up in days to come $(27.8 \%)$.

Most of our respondents experienced generalized suffering because of the pandemic but for some respondents their sufferings were more personalized due to the lockdown, yet the discussion around it is negligible. For instance, one respondent's father was tested positive for COVID-19. Given the stigma around it, she shared how the threat of contagion has revealed who are their well-wishers and who are not as no one helped her family in these times. Being in a precarious situation like that, her studies also suffered along with constantly living with fear.

Additionally, seeing the conditions of the outside world i.e., people dying, poor condition of migrant workers, limited hospital beds, poor infrastructure and increasing number of containment zones, has increased the stress level causing anxiety in many. With the outbreak of the pandemic and the news related to it, many of them said that they didn't feel like reading news because what they see and hear is all negative things which makes 
them very stressed and upset. Mr. Ritwik Awasthi ${ }^{4}$ mentioned that it is very worrying that there is a lot of unstructured knowledge available on the internet creating limiting and false perceptions, which is not based on any evidence. Although there was scarce information about it, some of our respondents also discussed the impact of social media and abundance of information on various digital platforms. While some are happy getting access to different social media contents, some have decided to take a break from their social media platforms and detoxify their minds.

It is noteworthy that since the threat of COVID-19 has increased, coping strategies and solution based discussions on anxiety, fear and depression have become quite widespread. Dr. Vishal Khare who is a registered kinesiologist and also works in the field of Osteopathy, believes that mental health is more important than physiological health because it drives us. He mentioned how high levels of anxiety may turn itself into depression. He highlighted different ways to reduce the mental stress which includes visualization techniques, breathing techniques, exercise etc. Interestingly, most of our respondents addressed their concerns of anxiety and fear by using various coping strategies like cooking, journaling, dancing, talking with friends, practicing yoga, meditation and various relaxing activities but none of them mentioned addressing the problem directly by talking about it. The taboo around the discussion on issues of anxiety and depression was evident from the way many of our respondents were either uncomfortable or offended at the mention of these terms. They responded better to the use of the terms 'fear', 'anxious', 'tension', etc. Dr. Khare also pointed out that because there is less awareness, social stigma around mental health is intense and pervasive. Most people will usually tell each other to deal with it but will never tell them that they need to talk to someone or seek help.

Thus 'stigma' emerged as an important category for us to understand the silences around discussions on mental health. In a televised discussion on NDTV in 2017, Chaitali Sinha and Dr Shyam Bhat ${ }^{5}$ emphasized how stigma and shame associated with

4 Mr. Ritwik Awasthi is another professional we interacted with. He is a life coach who is currently working on a solution based application to engage with mental health.

5 Chaitali Sinha is a psychologist at HAQ: Center for Child Rights in India and a practitionerresearcher with the global Mental Health Innovation Network and Dr Shyam Bhat is a leading psychiatrist 
mental health affects the individuals and their access to proper care (quoted in Taniparti, 2018). Our study also showed that mental health is often subjected to shame and thus people are embarrassed to talk about it for fear of being judged and labeled. Sharing one's vulnerabilities often solicits judgements, and reduces the individual to a subject of gossip. Social pressure to be 'normal' often results in lack of access to much-needed psychological care.

\section{DISCUSSION}

The impact of the pandemic on students is visible from the data collected during the course of the study. For the respondents, individually, the impact and experience may seem subjective but as a whole, common ground can be found. This common thread is not only because of the event of the pandemic which has directly or indirectly affected every single person across the world but that there are groups like the students that might be more prone to it for various reasons. Dr. Daniel described 'panic attack', an excessive form of anxiety as the most common mental health problem amongst the students. He shared that there is a high chance that during and after the pandemic, more students would be developing common mental health disorders like, anxiety, depression which might lead to self-harm and suicide.

Talcott Parsons (1959) stated that families performed an important role for individuals and society in keeping people stable especially when life becomes difficult, challenging and frustrating. From a functionalist perspective, socialization is the process through which people learn how to behave in society and understand what is normal and what is important. This is an essential process for society to work: there needs to be a broad agreement about these things to prevent people from behaving in an antisocial way. However according to conflict theorists, the family works toward the continuance of social inequality within a society by maintaining and reinforcing the status quo. Conflict theorists have conceptualized the family as a social arrangement benefiting men more than women. As it emerges from the responses, the bonds within the family setting (social integration) strengthened mostly in such families which had cordial relations amongst the family members even in the pre-pandemic period. The pandemic induced lockdown may have led to some disagreements but they were temporary. However, fights accentuated in families where conflicts and disagreements existed amongst the 
family members even in the pre-pandemic period. This was most evident in gender dynamics within the family which became more pronounced during the lockdown. A research study on "gender discrimination in the Family" by Bharadwaj et al. (2020) mentions that parents discriminate among their sons and daughters in ways that could have important and long-lasting effects and leave them scarred for life, leading to mental health concerns. Thus, family may not always be a loving and nurturing space which the popular opinion believes it to be thereby leading to less social integration. Mr. Awasthi said it is important for an individual to have acceptance and expression of emotions in a safe and supportive environment, which is something that does not come overnight, it has to exist from before (pre pandemic conditions) which will help people to deal with the pandemic. It is important to build resilience. Thus, with regard to the relationship between family and mental health, if the family is a safe space for acceptance and expression then the individual is better equipped to deal with mental health problems.

As revealed by the findings, our respondents were most worried about issues related to academics and their future plans. The prospective move towards digitization of education has been in the offing for quite a while and was opposed by students and faculty alike. But in the current situation, the shift towards online teaching and learning has been sudden with little time for students and faculty to adjust to the change/s. Additionally, as is pointed out by a number of people, the current pandemic situation requires more than just an emphasis on completion of the syllabus or conduct of exams, so as to ease out the transition for the students. The shift has been carried out without any proper evaluation which also raises concerns about the real purpose of education.

In an episode titled "Don't Normalize 'Online Education'| Cultural Matrix" on the channel The New Leam, Sociologist Avijit Pathak (2020) discusses the problems with the possible 'normalization of online education'. He stated that online education may be seen as enabling and democratizing the process of education but there are limits to this process. It is imperative to understand that education is not only dissemination of information (finishing the syllabus and grading the students) as is underscored in the current response of authorities in the form of online teaching and learning. Rather, it is to aid in the overall development of the young in a society. He further stated that in the 
present situation, one needs to rethink the purpose of education to equip the students with emotional and intellectual tools to live through the times they are in. The lack of such interaction and the push towards completing the prescribed syllabus, creating an illusion that everything is normal has only added to the woes of the students who are already perturbed with their situation.

The contemporary discourse on education locates it as a means to an end. Thus, most people think of education as a means to maintain the status quo (for people belonging to a good socio-economic location) or for upward social and economic mobility. This view has been further crystallized by the neo-liberal market framework that prioritizes the discourse of individual talent and merit rather than looking at various structural factors. It then has two implications. Firstly, it fails to recognize educational institutions as comprehensive spaces that offer opportunities for an all-round development of the students. Families (primary source of socialization) and educational institutions (secondary source) provide opportunities for personality development. Many students come to metropolitan cities like Delhi as they promise a better environment for learning and an all-round development. Moreover, colleges and schools offer various opportunities to engage in both co-curricular and extra-curricular activities. Anjum Khan (2019) has discussed how co-curricular activities teach a student social and intellectual skills, moral values, personality progress and character appeal, and how they go hand in hand with academics. Students often associate their lives more with their peers than with their family members. In many cases, our respondents talked about family like relationships outside the familial setting which was a strong support system for them. They distinguish between families they are born in and the families they choose and even though they may connect with their friends over virtual platforms, it is not the same. The current alternative of online classes might take care of the academic needs of students, but in other aspects it seems to be lacking. It once again raises the question, what is the role of education in the lives of students and what are the demands it makes on them. Is it meaningful only for making sure that the economy gets its workers or is it making holistic members of society?

Secondly, in contemporary neo-liberal economic framework, skill and academic enhancement activities which will train people to take their place in the economy are 
considered productive. Productivity can be understood as optimizing time. Productive activities contribute significantly to either intellect, creativity, passion or personality of a person. These activities are not meant for enjoyment, rather should be goal oriented. Leisure on the other hand involves activities of pure enjoyment and are considered a waste of time since there is no economic value attached to them. As it emerged in our study, productivity and leisure seem to occupy two opposite ends of the spectrum, where being on the productive end is not only considered beneficial for a person but also socially acceptable and if one is not being productive, then s/he is 'wasting time'.

The pressure to be productive and to perform was also visible in the familial spaces that our respondents are confined to. Most of our respondents belong to the middle class. We look at the middle class as a salaried professional class which has been instrumental in creating a certain discourse of middle class values and ethics which includes prioritization of education over other things and looks at hard work as a path towards becoming successful in life (Deshpande, 2003). It further creates a set of societal aims, objectives and expectations that each individual should strive to achieve. In contemporary situations being successful is increasingly related to one's economic growth which is connected to education, productivity, and results. This puts a lot of performance pressure on students to meet societal expectations which are also expectations of their families. This might be more difficult to negotiate with in joint families. Veena Das (1976) had opined that the child is not just the child of the mother, but that of an entire family. All members of the family have a say in the way their lives should be shaped. This was hinted at by some of our respondents as well who saw the family as the most important part of their lives, more so in the event of the lockdown.

It is through their interaction within the family and spaces of education, that our respondents constructed their sense of self. Invoking Mead and Goffman as discussed in the introduction, we can argue that in the case of our respondents, the pre-pandemic experience with family and education system coupled with the changes brought about by the pandemic has raised serious concerns about themselves. A feeling of having failed to meet societal expectations has significant implications on an individual. The students may feel less integrated or overly regulated affecting their mental health as was evident in the responses of most respondents in our study. 


\section{CONCLUDING REMARKS}

The study was conducted with the aim to arrive at a sociological understanding of the impact of COVID-19 on mental health, specifically stress-related issues of students. Taking a sociological perspective, it is argued that psychological well-being and distress are related to several general aspects of social life: the degree of social integration, inequality, and meaningful collective belief systems. Consequently, the study attempted to transcend the psychological underpinnings of mental health concerns and looked at experiential realities of the individuals in relation to their built environment which helps us understand the differences in degrees with regard to their coping mechanisms and individual resilience. It is here that we find social institutions of family and education playing an instrumental role in inflicting and also helping in the pandemic induced stress and anxiety among the students. Hence, the prevailing interrelationship between mental health, family and education were explored since for a student, family and education are the two most significant institutions. As demonstrated above, the respondents found it difficult to adapt to the new changes in the education system which did put a lot of pressure on them leading to feelings of frustration, anger and fear. In the context of family there was a mixed opinion, portraying both the supporting and conflicting sides of it. The pandemic brought about many changes and continues to do so in the institutions of family and education. This was understood through the concepts of productivity and leisure, deeper meaning of space and privacy, and prevailing stigma related to mental health problems. Through an interrogation into our respondents' opinions about the effects of online teaching and learning process, dynamics within the family, ideas of productivity and their immediate and long term fears and anxieties, the study contends that social realities are a result of collective experiences, ideologies, opinions and socio-cultural systems. These have a huge impact on the way an individual develops resilience in any situation, including the current pandemic, they find themselves in.

\section{CONFLICT OF INTEREST}

The authors declare that there is no conflict of interest.

\section{ACKNOWLEDGEMENT}


We would like to express our gratitude to the Centre for Research, Maitreyi College for endowing us the opportunity to conduct this research under the Summer Internship Programme, 2020. We are extremely grateful to all our respondents and key informants for being generous with their time and providing us with the data for our research, especially in these unprecedented times. Without their valuable support, we would have never been able to complete this research. We are also thankful to Dr. Gopi D. Tripathy from the Department of Sociology, Maitreyi College for her continued and valued guidance throughout the completion of this research. We would also like to thank the anonymous reviewer/s for their comments and suggestions that helped us improve our work.

\section{FUNDING}

None

\section{REFERENCES}

Bharadwaj, P., Dahl, G. B., \& Sheth, K. (2020). Gender Discrimination in the Family. Retrieved June 30, 2020, from https://econweb.ucsd.edu/ gdahl/papers/genderdiscrimination-in-family.pdf

Chopra, R., \& Jeffery, P. (Eds). (2005). Educational Regimes in Contemporary India. New Delhi: Sage Publications.

Das, V. (1976). Masks and Faces: An Essay on Punjabi Kinship. New Delhi: Oxford India Paperbacks.

Deshpande, S. (2003). Contemporary India: A Sociological View. New Delhi: Penguin Books.

Durkheim, E. (1897). Suicide: A Study in Sociology. Translated by John A. Spaulding and George Simpson, edited with an introduction by George Simpson. New York: The Free Press, a Division of Macmillan publishing Co., Inc.

Express Web Desk (2020, June 2), “Kerala: Class X student takes own life allegedly due to lack of access to virtual classes" in The Indian Express. Retrieved June 30, 
2020, from https://indianexpress.com/article/india/kerala/kerala-class-X-studenttakes-own-life-allegedly-due-to-lack-of-access-to-virtual-classes-6438832/

Goffman, E. (1956). The Presentation of Self in Everyday Life. New York: Doubleday Horton, P. B., \& Hunt, C. L. (1985). Sociology (pp. 79-10) New York: McGraw Hill.

Joas, H. (1997). G. H. Mead: A Contemporary Re-examination of His Thought. USA: MIT Press

Khan, A. (2019, April 17). "Role and Importance of Co-Curricular Activities at School" in Jagran Josh. Retrieved June 29, 2020, from https://www.jagranjosh.com/ articles/role-and-importance-of-cocurricular-activities-at-school-1507643588-1

Mead, G. H. (1934). Mind, Self and Society. London: University of Chicago Press

Naha, A. L. (2020, June 02). "Kerala Class X girl ends life allegedly over lack of access to online classes" in The Hindu, Malappuram. Retrieved 30th June 30, 2020, from https://www.thehindu.com/news/national/kerala/kerala-class-X-girl-endslife-allegedly-over-lack-of-access-to-online-classes/article31728470.ece

Parsons, T. (1959). "The Social Structure of the Family”. In R.N. Anshen (ed.) The Family: its Functions and Destiny. New York: Harper and Row

Pathak, A. (2020, May 30). “Don't Normalize 'Online Education'| Cultural Matrix” in The New Leam (Youtube channel). Retrieved from June 28, 2020, https://youtu.be/bVI3jixse

Ray, M. (2021, April 4). "India reports 93,249 Covid-19 cases, highest daily spike in over 6 months" in Hindustan Times, Retrieved April 4, 2021, from https://www.hindustantimes.com/india-news/with-93-249-new-covid-19-casesindia-records-another-daily-spike-101617507580132.html

Sen, A. (1999). Development as Freedom. New Delhi: Oxford University Press 
Taniparti, N. (2018, May 11). “The Worries of 'Log Kya Kahenge' on Mental Health” in The Wire, Retrieved August 31, 2020, from https://thewire.in/health/ socialfactors-behind-the-stigma-that-surrounds-mental-health-in-india

World Health Organisation. (n.d.). Mental Health and Substance Use. Retrieved June 30, 2020, from https://www.who.int/mental_health/en/

How to cite this article: Bhargava, R., Borgohain, N., Naidu, P., Bhatnagar, S., Lakra, S., \& Shukla, V. (2021). Anxieties and Fears: A Sociological Study of Mental Health of Students in COVID-19 Pandemic. Vantage: Journal of Thematic Analysis, 2(1): 86105.

DOI: https://doi.org/10.52253/vjta.2020.v02i01.06

(C) The Author(s) 2021.

This work is licensed under Creative Commons Attribution 4.0 International License which permits its use, distribution and reproduction in any medium, provided the original work is cited. 